\title{
Life Experiences and Coping Strategies in Adults with Congenital Heart Disease
}

\author{
Esperienze di vita e strategie di coping negli adulti con cardiopatie congenite \\ E. Callus, ${ }^{1}$ E. Quadri, ${ }^{1}$ A. Compare, ${ }^{3}$ A. Tovo, ${ }^{1}$ A. Giamberti, ${ }^{2}$ M. Chessa ${ }^{1}$
}

Key words: congenital heart disease; coping and adaptation emotions; focus groups; grounded theory; health behavior; interviews; psychosocial issues

\begin{abstract}
Many adults with congenital heart disease (ACHD) have to face considerable psychosocial difficulties. The aim of this study was to explore the life experiences of ACHD patients, from when they become aware of having a condition, till after the open heart surgery they underwent. The study was conducted with the use of unstructured, in-depth interviews, performed on 11 patients (age ranging: $20-56 \mathrm{y}$ ) after they recovered from open heart surgery and a focus group, which included 16 participants (age ranging: $22-46 \mathrm{y}$ ). Both the interviews and the focus group were recorded, transcribed and analyzed according to Grounded Theory procedures. Our findings show that the condition of diversity is the core of the emotional experiences connected to ACHD. Feeling different and being perceived as being different are clearly interlinked and coping strategies adopted resulted as being influenced by this perception. This study also clearly outlines the importance of having an adequate perception of one's condition and the link between maladaptive coping strategies and an incorrect perception of one's heart condition. Results are discussed in order to promote psychosocial interventions within and outside of the hospital setting in order to improve the patients' emotional wellbeing.
\end{abstract}

\footnotetext{
IRCCS Policlinico San Donato, Pediatric \& Adult Congenital Heart Disease Centre, Milan, Italy

2 Human Factors and Technologies for HealthCare Centre - HTH, University of Bergamo, IT

IRCCS Policlinico San Donato, Department of CardioThoracic Surgery II, Milan, Italy
}

Indirizzo per la corrispondenza (Corresponding author):

Edward Callus

IRCCS Policlinico San Donato, Department of Pediatric Cardiology \& Adult with Congenital Heart Disease, Milan, Italy

Phone: +39 0252774707 - Mail: edward.callus@grupposandonato.it

\section{Introduction}

The population of adults with congenital heart disease (ACHD) is a highly heterogeneous one including many different types of heart defects of various severity and this entails very different life experiences ${ }^{1}$. Those patients who are born with a complex condition can be regarded as having a chronic condition because of the long term nature of the heart disease, the uncertainty of its course and prognosis, the signs and symptoms of the condition and also the restriction on their everyday lives ${ }^{2}$. ACHD encounter specific psychosocial challenges which may have an impact on their Quality of Life (QoL), emotional functioning, self-perception, and peer relationships ${ }^{3}$.

There are very few studies conducted specifically investigating the life experiences of this population.

No specific psychosocial outcomes referring to patients born with the same pathology have been cited in the pertaining literature; patients having the same condition can have widely varied experiences depending on many biopsychosocial variables ${ }^{4-7}$. Having said this, the theme of being different from healthy peers emerges very strongly in the literature when it comes to this population 18-11. In particular, one study was conducted in Belgium in 2005 by Claessens and colleagues 9 investigated the life experiences of ACHD. The qualitative research that they carried out outlined that feeling different was the central theme of the patients' lived experience. This feeling of being different seemed to emerge predominantly during adolescence, when physical performance and bodily appearance are very important. It was reported that patients perceive discordance between their world and the world of healthy individuals and that this, in turn provokes the normalisation process which recursively influences the feeling of being different. This dynamic process of normalisation is the description of the struggle that patients and their close relatives live through, in order to appear that in spite of the disease, they can also lead a "normal" life.

According to these authors, this dynamic process involves three factors that affect the way in which the patients live with their disease: the context that surrounds them, including their family and friends, 
the health care system, that is the type of treatment they receive as well as the professionals who are involved and the level of their competence and sensibility and finally their own personality characteristics 9 .

With regards to the family, there are two extreme positions: the overly protective parents who live the disease of their children as being disabling and do everything they can to protect them, ignoring or hiding the limitations that the disease involves or minimizing and compensating these limitations. On the other hand, there are parents who are able to show their children a realistic view of the disease and help them accept their limits. When this occurs the children find it easier to cope and feel less different from others. In contrast, when the parents are hyper-protective, this results in their children having feelings of inadequacy, helplessness and diversity, as well as being one of the reasons for the prolonged stay of these patients with their parents when they grow up .

When it comes to the medical aspects, the patients make a strong distinction between before and after the operation. In this second phase they experience significant changes in their lives because of the health improvements they have and they also report appreciating their life more. The patients also report that being well informed about the operation and what it entails, can reduce the feelings of insecurity and uncertainty about their condition. The perception of the condition and the patient's coping style was determined by specific attributes of the patients' personality including the locus of control 9.

Subjects with congenital heart disease (CHD) often have difficulties to plan their future and this often influences their relationships. Some of them are not comfortable to talk about their illness for fear of being rejected and the available literature outlines that being accepted by others is very important for them. There is a strong indication that the lives of these patients is strongly conditioned by the presence of their illness $18-11$. Understanding the life experiences of ACHD can help discover those factors which helped and hindered them in their growth. Additionally they can give us precious insight on how to improve the patients' stay during hospitalization, also by giving indications on how to train health professionals who handle these patients. Another final important contribution is that they can help us improve the patients' compliance and evaluate if they are utilizing maladaptive coping strategies which could lead to a negative prognosis. It is also important to keep in mind that there can be important cultural differences in the life experiences of this population.

Another issue which emerges in the literature is social isolation and lack of support. Verstappen and colleagues ${ }^{1}$ specify the importance of the interaction between patients with the same pathology, which characterizes "peer support". The emancipation which is experienced by these subjects due to perceived support seems to be a transformative experience of great value to themselves and to the family members involved. The possibility for this patient group to share their experiences with those who are facing their same issues and the expression of their needs seems to be especially important and it has a strong positive impact on these patients.

\section{Method and sampling}

The method of Grounded Theory was utilized to analyse the data 12 13; it was first developed by two sociologists, Glaser and Straus, during their collaboration in a research on hospitalized patients who were dying ${ }^{14}$. They defined it as being the general method of comparative analysis, and a set of procedures capable to systematically generate a theory based on data ${ }^{15}$. Since their first publications, there was a split in theory between them which was consolidated by the publication of Strauss of several works ${ }^{16}{ }^{17}$, followed by a rebuke of Glaser ${ }^{18}$.

Successively a constructivist approach was developed by Charmaz; she makes a distinction between objectivist and constructivist concepts of Grounded Theory 13; the former takes for granted the presence of a neutral observer whereas the latter $<<$ recognizes that the viewer creates the data and ensuing analysis through interaction with the viewed $>{ }^{19}$ p. 523 and this approach was utilized in the analysis of the data 20 .

Our choice to utilize the Grounded Theory 12 method and not the Phenomenology or the Discourse Analysis lies in the fact that it permits to focus the attention on how social structures and processes influence how things are accomplished through a given set of social interactions. In fact, the Grounded Theory method relies on theoretical sampling, which involves recruiting participants with differing experiences of the phenomenon so as to explore multiple dimensions of the social processes under study. The researcher continues to add individuals to the sample until he/she reaches theoretical saturation; that is, when the complete range of constructs that make up the theory is fully represented by the data ${ }^{21}$. This method has also been used to examine the lived experiences of ACHD in other countries, where the authors specify that it permitted to examine the core concepts of the experiences of these patients, as well as different interrelationships in their lived experiences 9.

A single, unstructured, in-depth research was conducted with ACHD patients who were hospitalized in our centre and who were due to have open heart surgery. The interviews were conducted in a quiet room and they were recorded with a digital recorder and they were successively transcribed. The duration of the interviews was that of approximately one hour. They took place after the intervention, once the patient was fully recovered. Approval was obtained from the Ethical committee of reference. The focus of the interviews was their previous life experiences, including the quality of their stay in hospital, in order to be able to develop psychosocial interventions aimed to support the patients which necessary ${ }^{22-24}$.

In the Table 1 there is the list of the patients in the order they were interviewed. The total sample consisted of 7 males and 4 females, ranging from 20 to 56 years. Most patients had a complex condition and had previously undergone either catheterization or open heart surgeries. Only one patient had an initial heart defect which was of a cyanotic nature.

Besides the interviews, a focus group 25 held within the hospital, which had as a main objective the organization of a psychosocial 
peer to peer support network between adult patients was also included in the analysis ${ }^{26}$. Sixteen subjects participated, including 10 females and 6 males, ages ranging from 22 to 46 years of age, with different diagnosis of $\mathrm{CHD}$. All interventions were recorded and transcribed. More than one method to gather data was selected in order to allow the triangulation of sources so as to increase the credibility and the validity of the results.

In the process of initial coding, line-by-line coding was done. After that, focused coding was performed by grouping the initial codes, synthesizing and explaining larger segments of the data. Finally the relationship of the categories developed were explored in the process of theoretical coding, leading up to the proposal of a theory. The process was not linear and many times the raw data was referred to as the analysis and interviewing proceeded. Interesting areas which emerged during interviews were explored in the following ones if not brought up spontaneously by the patients ${ }^{20}$. The coding process was done independently by two psychologists and successively an agreement was reached when there was a divergence.

\section{Results}

As can be noticed from Figure 1, all the categories were organised under 3main categories: limitations and resources of congenital heart disease $(\mathrm{CHD})$, memories during hospitalization and coping strategies.

In turn these main categories all form part of the core category of "Having the condition and being different as a consequence". Here are the categories which emerged followed by an in-depth description of each one:

\section{Core category: Being different}

Being different from others who are healthy and do not have the condition is the core category which emerges strongly in all interviews with the patients. The consequences (which are not necessarily negative) and limitations due to their condition, besides the visible signs of the illness (cyanosis, scars and digital clubbing), remind the patients that they are different from other people, and so do their memories of all their hospitalization; the coping strategies adopted are a reaction to this perception and the associated feelings related to it. The most clear and touching quotation of being different was provided by a 21-year-old male patient, having a severe condition. At one point in time, his physical limitations increased

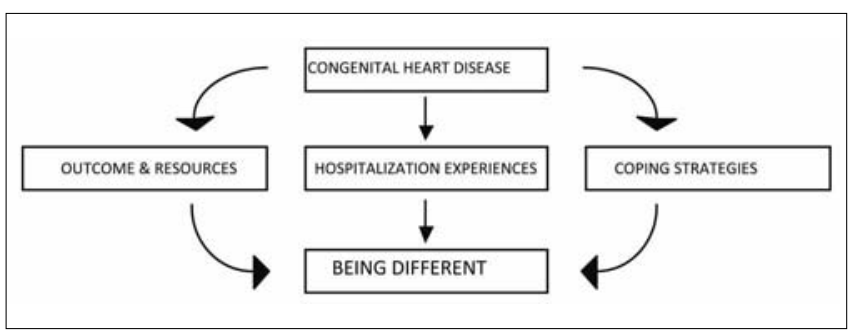

Summary of categories emerged from narratives so much that he felt a greater difference between himself and the others, and he wondered what he was going to do.

Whereas before I wasn't that bothered that I had heart prob-

lems, this thing over here differentiated me completely from

others and I started to feel a bit sad, and so I thought "what

shall I do now? Am I going to remain like this all my life?".

In fact this difference for him was too heavy to bear, and he was ready to risk everything in order to gain at least a minimum level of physical functionality which would have enabled him to do the basic things he was used to doing, even undergoing a heart transplant.

Feeling different and being perceived as being different are obviously connected, because the construction of our self-perception greatly depends on the feedback of others. Patients often report the others seeing them as being different, but not only in a negative way. An interesting thing about CHD is that the illness is not usually apparent to others, unless there is a visible scar which is also not covered by clothing, or the patient is cyanotic.

Another important result is that patients are often concerned about how others will view them, especially because CHD is not a condition which is well known. In fact, some of them show concern at the possibility of being seen as crippled and others feel angry because the ignorance of other people caused embarrassing situations which made them suffer a lot.

\section{Limitations and resources when having $C H D$}

Having a CHD involves becoming aware of having restrictions others around you do not have, and the process is different for all patients. A strong link emerged between the awareness process and the coping strategies adopted by the patients later on in life. As outlined in the core category, the consequences of having a CHD are not only negative; they also help the patients to have a greater sensibility and maturity and to appreciate life more. It is important to focus on this when providing support to these patients.

\section{- Dealing with physical limits in childhood and adolescence.}

CHD entails having restrictions in various aspects of life, from childhood, and having to undergo changes in lifestyle, especially due to the feeling of tiredness which the majority of the subjects report ("I was tired, I was going down the stairs and I felt....heavy). The patients associate the beginning of school with the perception of the proper limits linked to the illness and with feeling different ("the problems increase because as you might understand: damn the others haven't got it").

The patients' parents and their family play a very important role, in how the patients see themselves, how they feel about themselves and how they behave towards the illness. When the parents of children with CHD do not adequately perceive and communicate the condition to their children this can have catastrophic consequences. Many patients remember that their parents told them that they cannot strain themselves a lot, and this is when they started to understand that they were different. Other patients report that their parents were overprotective and it seems that this led them to do the 


\begin{tabular}{|c|c|c|c|c|c|c|c|}
\hline Table 1 & & & & SAMPLE CHARACTERISTICS. & & & \\
\hline Pt. $N^{\circ}$ & Sex & Age & Civil status & Diagnosis & OHS Int. & C. Int & NYHA \\
\hline 1 & $M$ & 56 & Single & Pulmonary Stenosis & 2 & 1 & 3 \\
\hline 2 & M & 22 & Single & $\mathrm{VSD}+\mathrm{Al}$ & 0 & 0 & 1 \\
\hline 3 & $\mathrm{~F}$ & 43 & Married & Tricuspid Atresia & 2 & 0 & 4 \\
\hline 4 & $\mathrm{~F}$ & 33 & Single & Aortic Valve Stenosis & 1 & 0 & 3 \\
\hline 5 & $\mathrm{~F}$ & 20 & Single & Tetralogy of Fallot & 2 & 1 & 2 \\
\hline 6 & $\mathrm{M}$ & 55 & Single & Aortic Valve Stenosis & 1 & 0 & 2 \\
\hline 7 & $\mathrm{M}$ & 21 & Single & Aortic Valve Stenosis & 0 & 0 & 3 \\
\hline 8 & $\mathrm{M}$ & 20 & Single & Transposition of great arteries + ASD & 2 & 2 & 2 \\
\hline 9 & $\mathrm{M}$ & 25 & Single & Tetralogy of Fallot & 1 & 3 & 2 \\
\hline 10 & $\mathrm{M}$ & 35 & Single & VSD + Double outlet right ventricle & 1 & 1 & 2 \\
\hline 11 & $\mathrm{~F}$ & 56 & Married & Tetralogy of Fallot & 2 & 4 & 3 \\
\hline
\end{tabular}

Sospensione dell'allattamento al seno esclusivo: $0=$ sospeso; 1 =prosegue

Table 2

APPLICATION OF COPING STRATEGY CLASSIFICATIONS TO SAMPLE DATA.

\begin{tabular}{lll}
\hline & Approach & Avoidance \\
\hline Cognitive & $\begin{array}{l}\text { Cognitive approach coping } \\
\text { Not being alone with this condition } \\
\text { and comparing oneself with others } \\
\text { in worse situations }\end{array}$ & $\begin{array}{l}\text { Cognitive avoidance coping } \\
\text { "Accepting the inevitable" } \\
\text {-Utilisation of irony and humour } \\
\text { - Downplaying the condition: from minimisation to complete denial }\end{array}$ \\
\hline Behavioural & Behavioural approach & Behavioural avoidance coping \\
\hline
\end{tabular}

Sospensione dell'allattamento al seno esclusivo: $0=$ sospeso; $1=$ prosegue

opposite of what they were told. In particular, one patient male patient reports that:

my mother used to tell me, don't run, don't play ball, I couldn't

do it she always told me but I used to do it even at work, I used

to do tiring jobs

On the long run, overprotection entails a delayed entry in the adult phase, because if the parents preclude their children from experiencing many things since when they are very young, they convince themselves that they have no choice but to depend on them ("it's a viscous circle which one has to end in order to live one's life truly"). It is possible that the children's behaviour also influences the parents because this patient in particular says that he was always very lively; so overprotection and being lively become a vicious circle. It seems that being told that one has a condition when they are very young, in a simple manner, helps them to develop a good awareness, and as a consequence it seems that they can deal with the situation better, as explicated by another male patient:

Honestly for me even in hospitals, it was normal, so I can't tell you when I started, that is my mother has always been the type to always say, obviously she wouldn't go in detail, but she told me, you are not a boy like the others, you have a little problem with your heart so you cannot do everything, and as a consequence I don't know if I asked questions, which I probably did, but I think I reacted in this way, remaining calm.

Having to deal with physical limitations is also present in adolescence when the desire to do what is forbidden and to conform to peer pressure are even more present. In fact some of the patients have a very hard time accepting their limitations during this period. When things are explained clearly and without too much anxiety the patients grow up with an awareness of being different, and being restricted, but it does not make them feel bad about themselves.

Due to the physical limitations the patients sometimes feel they have no choice but not to participate in the activities their peers are involved in and this makes them feel excluded from others. This can result in isolation and choosing to remain at home.

\section{- Rejection, humiliation isolation and perceiving oneself as a burden.}

The physical limitations have often made the patients feel distance between themselves and others and sometimes the others willingly or unwillingly underline this difference. The rejection of the others seems to be linked to a need of being understood as people and not just as being ill people. ("Solitude is a nasty thing, referring also to the fact that there is a lack of knowledge and no possibility of finding someone to talk to....diabetics have a lot of support...for alcoholics, there are a lot of associations...teenage mothers...the voice of cardiac patients is an unheard one").

Some of the patients are reluctant to immediately tell their romantic partners that they have this condition, and some patients actually tell of being left because of this condition, either because their partners were in some way scared or because they could not handle it.

Sometimes cyanosis can be the cause of other people picking on the patients. When other people do not understand what the condition is they can behave in a certain way which causes shame, embarrassment 
and trauma in this population. In particular, the cyanotic patient in the sample describes two incidents at the sea which depict this.

Once a woman who was with a girl, who was about 20 years

old, held me from my arm while I was going down from the lad-

der (to the sea) and she said, Come up look what a violet mouth

you have, if you feel bad it will be my problem!.... and all the

people were looking, for me it was a trauma.

Another feeling the patients had in common was the fact that they were a burden, and that because of their condition they encumbered their family, their parents and their partners with heavy loads. Perhaps because of this, they often feel that they shouldn't share their worries with their parents to make them worry, keeping everything inside. Some of them also refrained from engaging in group activities or sports because they feared how others would feel if they felt bad in their company.

Also when the patients have a difficult physical situation, and they need to be taken around, they can feel that they are a burden for others. The fact that others have to take care of them can make them feel guilty, even though they have no control over their physical health.

- Shame due to rejection and visible signs of the illness and it's limitations.

Some interesting gender differences appear when it comes to the surgical scar. It is perhaps the most visible sign of having the condition, after cyanosis. The female patients seem to be particularly sensitive about it, and even though time it seems they bother less about it, a small influence remains; for example in the choice of what clothes to wear. Most of them were bothered when people asked them what happened to them so they wear clothes which cover it up, or they use foundation.

And then the scar, I didn't want others to see me wearing the bathing costume with the scar from the 12-year-old boys, you start growing up, it was a trauma I used to see my girlfriends all healthy and myself with a scar from here to here I used to put on one piece costumes"

(Later in life)

"The sweaters always high necked but I started wearing bikinis.

The scar is not only a problem for esthetical reasons in women, it is also the means by which other people notice what the patient could have passed through, and for this reason it is often covered. When it comes to the male patients, and how they perceive the scar, it seems that they are also bothered by it in the beginning but not as much as the females, also because sometimes there is the possibility to cover it with body hair.

- Sexual and reproductive issues; sexual performance, pregnancy and child rearing.

Most of the men in the sample commented on how having the condition also affected their sexual performance. The implantation of mechanical cardiac devices can give rise to embarrassing situations during intimacy.

I noticed that when meeting new people, suddenly my problem came into my mind, that is that with the valve, when one is particularly excited the person close to you can perceive it, so my problem was that capacity the other had to understand... when I used to like someone it used to stop me, that is I had some hesitation and I used to tell myself, how do I deal with this thing? Whereas sexual performance emerged during the interviews with the male patients, the issue of pregnancy and child rearing was more prominent for the female patients; they expressed a lot of doubts regarding the possibility of having children and some of them knew that it was not possible for them.

\section{- Positive outcomes: feeling more mature and being pampered.}

Having the condition does not only entail having limitations but also positive outcomes. Many patients declare that as a consequence of their condition, they feel they have matured more quickly and they can appreciate the important things in life better.

That is in order to deal with these things you have to strengthen yourself, think positively and on the one hand a bit more of maturation, maybe more quickly than others and trusting others, doctors, parents, so for sure the positive things were also more present.

\section{Hospitalization experiences}

In all the interviews of the patients, their experiences during hospitalization were described. The patients mainly outlined the difficult moments they passed through and also they relationship they had with the health personnel, including both positive and negative examples and at times ambivalence.

\section{- Difficult moments during hospitalization: experience of intense suffering.}

Strong adjectives such as "nightmare" and "Calvary" are used to describe the patients' experiences during hospitalization. It is not surprising that some of them also describe developing a phobia for white coats when they were children. Most of the patients feel that they do need support during the whole hospitalization process and many have emphasises that they need to be supported especially when they are in the intensive therapy unit. They would like to have the company of someone when they come into their senses from after the operation. Referring to the hospitalization process:

.... a preparation that is, someone who talk to you before and

also the psychological state when you wake up there, there is

nobody because there is nobody in the intensive therapy unit

(ITU) because nobody can be close to you according to me this would be useful.

In fact in the moments preceding the interventions the experience of uncertainty about the future and fear of death is common: "in the last week before the intervention I thought I would not make it, I was very scared", "a sort of doubt arose in me, and I told myself: - what if this were the last day of my life?".

Several patients declared that a figure like a psychologist could help them prepare better to undergo the intervention, and could also be an important support for the fear they feel. 
- The relationship with the medical staff.

The patients were ambivalent towards the medical staff and they gave examples of positive and negative experiences they had.

On the one hand the patients know that their life depends on the medical staff, they are grateful when they get help, on the other hand, the frustration of being unhealthy, needy and dependent may be vented out on the personnel, in the form of: "you are incompetent, you haven't done enough, it's not right etc." Or perhaps, there are certain things which have not been done well and this also exacerbates this feeling, or justifies the venting out which becomes accentuated. The ambivalence towards hospitalization can be seen in this narrative;

I was treated very well at that hospital for goodness sake, they made my fever go, they told me I had to be operated again so it was fine with me, but when they told me that I had to be operated upon again I said I won't go there, certainly not because if I have to undergo another operation after 4 years when it had to last 15, I won't go.

Reports of dignity violation identify a sense of generalized disrespect or even gratuitous nastiness that pervades some health care settings ${ }^{27}$. It is therefore very important that the hospital staff is sensitive to certain aspects of the patients, and that they highlight positive things, and avoid being insensitive, especially during hospitalization when the patient needs to be operated upon.

People with CHD want to feel that they are normal people, who have to face difficult conditions. They do not want to be identified with the disease, but want to be perceived as being normal people, who have to deal with difficult situations and health problems. When this attitude is adopted by the medical staff they feel better.

In the interviews and focus groups it emerged that explaining things in a simple way with the use of diagrams, showing the ICU and the operating theatre before the intervention can be very helpful during childhood.

The relationship with the medical staff was often brought up by the patients who outlined the following malpractices.

- "Colluding” with the patients' (implicit) requests.

Professionals who work in this field should have the capacity to recognise to prevent things such as this from happening and help the patients to elaborate a more accurate sense of self, trying to find an equilibrium between not demoralising the patient too much, but at the same time, making them aware of the possible risks that some inadequate behaviours (such as physical activity) can have.

Sometimes it appears that the patients do not want to know what the operation entails and what the consequences will and can be; this could be the part of a defence mechanism which allows them to handle the situation. It would be better to support these patients, and let them know, in a delicate manner what is going to happen, otherwise they will probably suffer the consequences when the awaken after the operation.

This occurred in one of the patients; he didn't want to know much about the intervention, because he could not handle it, and this resulted in him feeling very bad when he woke up. The health personnel should be aware that patients could not want to know details about the operation because they are scared, and that this could have negative consequences when the patients recover from the operation.

after the intervention as I was waking up I asked myself, you didn't want to know what will happen to you, how your life will be, how your future will be, that is what this operation will entail, what you will be able to and in that moment I regretted not being updated on what had happened to me. A psychological preparation from the beginning of the hospitalization could help prevent this from happening.

\section{- Insensitivity of the medical staff.}

When health care providers do not take into consideration the patients' knowledge, skills, perceptions, concerns, needs, and feelings they also injure their dignity ${ }^{27}$. If the medical staff is insensitive, this can cause a lot of problems and a lot of fear in the patients, especially in very delicate moments such as just before a procedure, especially if that procedure has not been done before by the patient, and there is a lot of fear. One patient describes being told about how risky the operation is in a very insensitive way by a nurse:

she told me "well one person passed away whilst he was doing

$i t$, he was 25 years old. The operation is hard and many don't

make it." I did not speak

From this example the necessity of the medical staff receiving training in the psychosocial handling of the patients is quite evident. Other examples of medical staff being crude to the patients also emerged from the interviews with other patients.

\section{- Misdiagnosis and its catastrophic consequences.}

The CHD population is a very particular population, and it is necessary that specialists who are capable to diagnose conditions correctly work with them, otherwise there can be catastrophic consequences, as described by one patient who even though was manifesting many physical problems, was told that "she had the heart of a lion". It is interesting that even though this had extremely negative consequences on her life, she is very controlled when expressing her anger. The same patient describes how the cardiac surgeon who had misdiagnosed her tried to hide his incompetence by blaming the family for neglecting her.

\section{Coping strategies}

As patients describe what they have been through, a description of their coping strategies emerge spontaneously. The evaluation of a coping strategy being adaptive or not is not straightforward; the patients themselves, whilst they are narrating their experiences, sometimes evaluate some strategies they utilized in the past as being non adaptive. This gives us important insight on what to look out for during the rehabilitation process. 
The theoretical framework of Moos and Holahan ${ }^{28}$ was successively utilised to categorise these coping strategies. They specify that there are two approaches when it comes to classify coping skills: the emphasis of the focus of coping, that is whether people with chronic illnesses actively approaches a problem or if they avoid it (approach - avoidance) and the method of coping - whether the primary responses entail cognitive or behavioural efforts (cognitive - behavioural). By combining these two approaches they specify four broad domains of coping: cognitive approach coping, behaviour approach coping, cognitive avoidance coping and behavioural avoidance coping.

\section{Cognitive approach coping}

- Not being alone with this condition and comparing oneself with others in worse situations.

The fact that there are other people who have suffered the same thing, who have the same kind of scar, can make these patients feel better. Saying to oneself that things could be worse and that there are other people who have worse conditions seems to be a good strategy to mitigate negative emotional states. Sometimes not only imagining that there are people out there with worse conditions, but also having first-hand experience of people who they perceived as being worse, and who eventually passed away was a source of inspiration and strength.

"I always told myself that there are worse cases in life than mine because I had an ugly bereavement in my family and the courage of the person who I lost used to give me strength."

\section{Cognitive avoidance coping}

- Accepting the inevitable.

One of the patients provides a very touching description of this phenomenon in the beginning of the interview. He describes how he has always felt different and limited, and that this has caused him suffering, but at the end of the day, one accepts the inevitable and moves on.

Since always, I was born this way, so since I have never led a normal life, as a healthy boy, I never thought about the possibility "if I hadn't have got sick I wouldn't have this problem", I always though, I have it if I live with it it's better for me, I accept the inevitable.

It seems that the fact of accepting the inevitable seems to make suffering more bearable. It could be possible that since some patients are born with this condition, and they are used to having it since when they are born, they perceive certain limitations as not being so hampering.

\section{- Utilization of irony and humour.}

The utilization of irony and humour can be a great resource to deal with discomfort caused by the condition. One of the patients handled feeling different from others because of the "tic" of the mechanical valve by using irony; a strategy which seemed to allow him to handle the situation with much more ease. by using irony, that is I didn't use to say anything and then depending on the person, their capacity and cultural level, I used to invent stories (patient giggles) even which were very imaginative, I also told a very simple girl that I was an alien (patient giggles again).

\section{- Trust in faith.}

A few patients rely on faith to cope with the difficulties, and this seems to give them hope and to be a good coping mechanism ("I have always searched of hope when I was scared that things would go wrong. One must have faith in all things; the faith in God led me to believe this").

- Downplaying the condition: from minimization to complete denial.

Often in these patients we can see that they minimize their physical limitations, downplaying how serious they are, or their effects on their life. This phenomenon can happen at different levels of awareness. Sometimes the patients cannot handle knowing what the surgical operations they have to undergo entail, and what consequences they could have, and they chose not to ask about them or not to let the medical staff explain things to them clearly. This can leave the patient with a sense of anxiety once they recover from the operation.

Many times the physical symptoms are ignored, until something quite serious which cannot be ignored happens. The mistaken belief that things will get better on their own is a false belief held by quite a few of the patients, and their relatives, especially at the beginning of the illness, possible because it is hard for them to face such a condition, but this erroneous perception could also have been caused by a misdiagnosis.

For example one patient who knew about his condition, waited all night before checking out what the problem with his breathing was. It appears to be quite strange that he didn't attribute this to his heart. In another case, a patient used to feel that something was wrong, but he used to ignore his physical symptoms, and continue doing manual jobs. This has even lead (together with other factors, such as his mother and siblings ignoring it and a low level of education) to the discovery of the condition much after in his 50 s with consequent catastrophic consequences on his health.

\section{Behavioural approach coping}

\section{- Getting support from family partners and friends.}

The support of family and partners seems to be essential for these patients. Nearly all patients outline how important their parents, partners, relatives and friends have been, even though sometimes the parents can provide extra stress during hospitalization because they do not manage to deal with their own anxiety. For this reason it is also important to supply psychological support also to the parents and relatives visiting the patients, in order to help to be a resource for the patient as much as possible. 


\section{Behavioural avoidance coping}

- Defying limits and its possible consequences:

Many patients describe this coping strategy; testing the limits, seeing until what point they can do what they are not supposed to do in order to prove to themselves that they are not really that ill, and that different from others. This was described very accurately by one of the patient:

And I used to tell myself, the illness, that is I have to win the illness anyway, the illness cannot impose on me what to do if I don't want to do it and so I'll do some things and I'll see until what point I will arrive, this was my reasoning.

On the one hand I tried to combat the illness doing the contrary

of what I had to do and on the other hand I corrected myself alone.

This defiance of the limits may be more prone during the adolescent and early adulthood phase, after it seems that the patients feel a bit resigned and adjust to their condition, also because they often have scary experiences.

\section{Discussion}

The total sample analyzed was quite numerous (28 subjects when including the patients interviewed and the participants of the focus group), having analyzed two different sources of data, encountering the same elements outlined in the various categories, we believe that saturation has been reached.

By using the GT, the triangulation of sources, the careful description of the procedure and the continuous analysis of the data gathered, the credibility and the reliability of the research is increased 29 . In this research, the fact that some patients do not have a realistic perception of the severity of their condition emerges clearly. The analysis of these patients experiences can give us some hypothesis regarding of why this occurs; we can assume that the fact of being different emerges strongly and this underestimation could be an attempt to "normalise" the situation.

For normalisation, Claessens and colleagues (2005), intend the "process during which patients and their families struggle for a life that is in harmony with that of their healthy peers; a management strategy of the family". The feeling of being different emerges especially during adolescence, and age in which physical performance and appearance have an important relevance. The young adults, on the other hand, have more difficulties in the work and relationship spheres.

\section{Influencing factors}

It was very interesting to see the clear connection between how the upbringing of the patients, their social status, education and the context where they were brought up had a deep impact on the coping strategies utilized.

The patients themselves describe avoiding coping strategies they had utilized previously as not being adaptive, especially when it comes to the defiance of limits. Other avoidance strategies, such as accepting the inevitable and the utilization of humour did seem to be adaptive from what they patients described. Denial on the other hand might have been functional at times, such as before an intervention, but it seemed to have consequences anyway, and often it lead the patients not to acknowledge cardiac related symptoms which could have put their health in danger.

Interestingly, the correct perception of the severity of an illness was paramount in handling having a $\mathrm{CHD}$, an underestimation of the condition is associated with maladaptive coping strategies which could lead to risky health behaviours.

The link between the underestimation of the condition and maladaptive coping strategies is a theme that had not yet been dealt with in the literature: the direct comparison between disease severity perception and evaluation, the analysis of the interviews has outlined that an inadequate perception of one's severity can lead to maladaptive coping strategies which can put one's life at a risk.

For this reason it is essential to help these patients to get a more accurate perception of their condition and to try to discover, together with them adaptive coping strategies to increase their compliance with the medical team and to help them deal with their condition more effectively, also by empowering them to use the resources which are already available to them.

Although the denial of one's condition can be a functional coping mechanism during certain stages of the illness and it could allow the patients to adjust, an extreme underestimation of one's severity could have very detrimental effects on one's health.

Whereas some of the patients themselves, identified and acknowledged that in the past, especially when they were adolescents, they enacted these kind of coping mechanisms, but then stopped when they became aware of how dangerous they were, there were some who showed no such awareness.

The current research shows that the feeling of being different because of the condition is the main issue when it comes to ACHD patients. This is not only the source of negative consequences; as many patients outline, it has made them stronger, mature more quickly, it has led others to see them in a certain light and chose them as partners and finally it has also led them to be pampered by others. Obviously the negative consequences also emerged, and they included isolation, fear, being ridiculed, having problems in many social spheres, such as finding an occupation and a partner.

Patients describe numerous difficult moments in their life, some of these related to hospitalizations experiences. In this research particular difficulties during recovery in the ITU emerge: quite a few patients outlined that the most difficult time was after the operation, when they could not move and they felt very helpless. (“...someone who talk to you before and also the psychological state when you wake up there, there is nobody because there is nobody in the intensive therapy unit (ITU) because nobody can be close to you according to me this would be useful"). So a support in that moment of their hospitalization experiences seems to be really important.

The individuation of the core category and of the other connected themes has provided some important suggestions when it comes to the psychological support and the creation of a peer to peer support 
system for this population in Italy. Meeting others who have the same or similar condition was found to be a good possibility for a positive reformulation and also an occasion of adaptive coping. A great need was found for support, understanding and for being known as people and not as ill people.

For this reason it is important that psychological services which maximize the possibilities of interacting with other patients are developed.

A major strength of this study is the use of interviews and the focus group. Both method, besides being useful to obtain data regarding the life experiences of the patients and to gain insight about useful psychosocial intervention, allowed the subjects to narrate their own experiences. An increasing number of studies have focalized on the therapeutic usefulness of narration, highlighting how the translation in words of traumatic experiences can have a positive impact on physical and mental health ${ }^{30}$. The construction of stories can result as being a natural human process, thanks to which individuals organize and remember events in a coherent way, integrating thoughts and feelings and managing, in this way to understand themselves and their experiences. Finally the utilization of the two different ways of gathering data was conceptualized in order to facilitate the triangulation of the sources; that is the research of the convergence on the conclusions by cross referencing different sources of information, one of the elements which determines the quality of a qualitative research 3132 .

\section{Limits}

The categories outlined result as being saturated, since no new data emerged when proceeding with the analysis of the interviews and the focus group ${ }^{25}$. These become redundant since when proceeding with gathering new data the categories and their properties are continuously confirmed ${ }^{15}$. In spite of this theoretical conclusion, it is difficult and controversial to establish precisely and in a reliable manner when a category is indeed saturated with any further data gathering being useless. ${ }^{33}$. In fact there isn't a valid method which establishes when the saturation of the data is reached and therefore this concept does not result to be clear on a practical level.

Some practical solutions have been proposed, as the " $10+1$ rule" by Francis 29 according to which researches should specify a priori how many more interviews will be conducted, without new shared themes or ideas emerging, before the research team can conclude that data saturation has been achieved ("stopping criterion"); at least 10 interviews will be conducted and if after the 10 interviews in which saturation is reached, another interview which confirms the saturation is done, the interviews can be considered as being sufficient and saturation reached.

\section{References}

1 Verstappen A, Pearson D, Kovacs AH. Adult congenital heart disease: the patient's perspective. Cardiol Clin 2006;24(4):515-29, v.
2 Moons P, De Geest S, Budts W. Comprehensive care for adults with congenital heart disease: expanding roles for nurses. Eur J Cardiovasc Nurs 2002;1(1):23-8.

3 Kovacs AH, Sears SF, Saidi AS. Biopsychosocial experiences of adults with congenital heart disease: review of the literature. Am Heart J 2005;150(2):193-201.

4 Compare A, Bigi R, Orrego SO, Proietti R, Grossi E, Steptoe A. Type D Personality Is Associated with the Development of Stress Cardiomyopathy Following Emotional Triggers. Annals of Behavioral Medicine 2013.

5 Compare A, Proietti R, Del Forno D, Vitelli A, Grieco A, Maresca L, et al. Vulnerable personality and takotsubo cardiomyopathy consequent to emotional stressful events: A clinical case report. Monaldi Archives for Chest Disease - Cardiac Series 2011;76(2):99-103.

6 Compare A, Germani E, Proietti R, Janeway D. Clinical psychology and cardiovascular disease: An up-to-date clinical practice review for assessment and treatment of anxiety and depression. Clinical Practice and Epidemiology in Mental Health 2011;7:148-56.

7 Compare A, Del Forno D, Callus E, Giallauria F, Vitelli A, Buccelli C, et al. Post-traumatic stress disorder, emotional processing and Inappropriate Implantable Cardioverter-Defibrillator Shocks: clinical consideration by a single case report. Monaldi Archives for Chest Disease - Cardiac Series 2012;78(4):164-70.

8 Berghammer M, Dellborg M, Ekman I. Young adults experiences of living with congenital heart disease. Int J Cardiol 2006;110(3):340-7.

9 Claessens P, Moons P, de Casterle BD, Cannaerts N, Budts W, Gewillig M. What does it mean to live with a congenital heart disease? A qualitative study on the lived experiences of adult patients. Eur J Cardiovasc Nurs 2005;4(1):3-10.

10 Gantt L. As normal a life as possible: mothers and their daughters with congenital heart disease. Health Care Women Int 2002;23(5):481-91.

11 Gantt LT. Growing up heartsick: the experiences of young women with congenital heart disease. Health Care Women Int 1992;13(3):241-8.

12 Starks H, Trinidad SB. Choose your method: a comparison of phenomenology, discourse analysis, and grounded theory. Qual Health Res 2007;17(10):1372-80

13 Walker D, Myrick F. Grounded theory: an exploration of process and procedure. Qual Health Res 2006;16(4):547-59.

14 Glaser BG, Strauss AL. Awareness of dying. Chicago: Aldine Pub Co., 1965.

15 Glaser BG, Strauss AL. The discovery of grounded theory; strategies for qualitative research. Chicago,: Aldine Pub. Co., 1967.

16 Strauss AL. Qualitative analysis for social scientists. Cambridge [Cambridgeshire] ; New York: Cambridge University Press, 1987.

17 Strauss AL, Corbin JM. Basics of qualitative research : grounded theory procedures and techniques. Newbury Park, Calif.: Sage Publications, 1990.

18 Glaser B. Basics of grounded theory analysis. Mill Valley, CA: Sociology Press, 1992.

19 Charmaz K. Grounded Theory: Objectivist \& Constructivist Methods. In: Denzin N, Lincoln YS, editors. Handbook of Qualitative Research, 2nd edition. Thousand Oaks: Sage, 2000:509-35.

20 Charmaz K. Constructing grounded theory : a practical guide through qualitative analysis. London; Thousand Oaks: SAGE, 2006.

21 Starks H, Brown Trinidad S. Choose Your Method: A Comparison of Phenomenology, Discourse Analysis and Grounded Theory. Qualitative Health Research 2007;17(10). 
22 Compare A, Kouloulias V, Apostolos V, Peña WM, Molinari E, Grossi E, et al. WELL.ME - Wellbeing therapy based on real-time personalized mobile architecture, vs. cognitive therapy, to reduce psychological distress and promote healthy lifestyle in cardiovascular disease patients: study protocol for a randomized controlled trial. Trials 2012;13.

23 Manzoni GM, Villa V, Compare A, Castelnuovo G, Nibbio F, Titon AM, et al. Short-term effects of a multi-disciplinary cardiac rehabilitation programme on psychological well-being, exercise capacity and weight in a sample of obese in-patients with coronary heart disease: A practice-level study. Psychology, Health and Medicine 2011;16(2):178-89.

24 Villani A, Malfatto G, Della Rosa F, Branzi G, Boarin S, Borghi C, et al. Disease management for heart failure patients: Role of wireless technologies for telemedicine. The ICAROS project. Continuità assistenziale nei pazienti con scompenso cardiaco: Ruolo delle tecnologie wireless per la telemedicina. II progetto ICAROS 2007;8(2):107-14.

25 Morgan DL, Bottorff JL. Advancing our craft: focus group methods and practice. Qual Health Res 2010;20(5):579-81.

26 Compare A, Molinari E. Depression and cardiovascular rehabilitation outcome in MI patients: The mediation role of quality of couple relationship. Psychology and Health 2004;19(SUPPL. 1):33-34.
27 Jacobson N. Dignity violation in health care. Qual Health Res 2009;19(11):1536-47.

28 Moos RH, Holahan CJ. Adaptive Tasks and Methods of Coping with Illness and Disability. In: Martz E, Livneh H, editors. Coping with Chronic Illness and Disability, Theoretical, Empirical, and Clinical Aspects. New York: Springer, 2007:107-26.

29 Francis J, Johnston M, Robertson C, Glidewell L, Entwistle V, Eccles M, et al. What is an adequate sample size? Operationalising data saturation for theory based interview studies. . Psychology \& Health. 2009:1-17.

30 Pennebaker JW, Colder M, Sharp LK. Accelerating the coping process. J Pers Soc Psychol 1990;58(3):528-37.

31 Mantovani G, Spagnolli A. [Qualitative Methods in Psychology]. Bologna Il Mulino 2003.

32 Grossi E, Compare A, Buscema M. The concept of individual semantic maps in clinical psychology: a feasibility study on a new paradigm. Quality and Quantity 2012:1-21.

33 Morse J. The significance of saturation. Qualitative Health Research 1995;52:147-9. 